\title{
Evaluation of the expression of C-kit (CD117) in ependymomas and oligodendrogliomas
}

\author{
Lisiane Silveira Zavalhia ${ }^{\mathrm{a}, *}$, Mirian Romitti ${ }^{\mathrm{b}}$, Gabriel Corteze Netto ${ }^{\mathrm{a}}$, Giovana Tavares dos Santos ${ }^{\mathrm{a}}$, \\ Rosalva Thereza Meurer ${ }^{\mathrm{c}}$, Arlete Hilbig ${ }^{\mathrm{d}}$, Mariana Bohns Michalowski ${ }^{\mathrm{e}}$ and Marlise de Castro Ribeiro ${ }^{\mathrm{d}}$ \\ ${ }^{a}$ Laboratory Research Pathology, Graduate Program in Pathology of Universidade Federal de Ciências da Saúde \\ de Porto Alegre, Porto Alegre, Brazil \\ ${ }^{\mathrm{b}}$ Graduate Program in Medical Sciences of Universidade Federal do Rio Grande do Sul, Rio Grande do Sul, Brazil \\ ${ }^{\mathrm{c}}$ Laboratory Research Pathology of Universidade Federal de Ciências da Saúde de Porto Alegre, Porto Alegre, \\ Brazil \\ ${ }^{\mathrm{d}}$ Department of Clinical Medicine of Irmandade Santa Casa de Misericórdia de Porto Alegre, Porto Alegre, Brazil \\ e Department of Pediatrics of Irmandade Santa Casa de Misericórdia de Porto Alegre, Porto Alegre, Brazil
}

\begin{abstract}
C$-kit is a proto-oncogene located on the long arm of chromosome 4. Its product, CD117, is a specific immunohistochemical (IHQ) marker that is associated with response to a potent tyrosine kinase inhibitor therapy with STI-571 (Gleevec $\left.{ }^{\circledR}\right)$ in chronic myelogenous leukemia and GISTs. In our study, we aimed to evaluate the expression of CD117 in glial tumors as this finding may guide therapeutic approaches for these brain tumors. Ependymomas and oligodendrogliomas, in formalin fixed and paraffin embedded blocks were assayed for CD117 immunoreactivity using anti-c-kit (CD117, DAKO). GISTs were used as positive control. We observed immunoreactivity of CD117 protein in $25.5 \%$ of tumors in both histological types. In oligodendrogliomas, there was an association between older age at diagnosis and positivity for $\mathrm{CD} 117$ ( $\mathrm{P}=0.039$ ). In addition, we observed an association between higher tumor grade (grade III) and positivity for CD117 ( $\mathrm{P}=0.007)$. No clinical association was observed in ependymomas $(\mathrm{P}>0.05)$. This study encourages further investigations, considering that CD117 may be a possible oncogenic factor in some glial tumors. In this case, tumors that express this marker may eventually benefit from a therapy with selective inhibitors of receptor kinases.
\end{abstract}

Keywords: CD117 c-kit, ependymomas, glial tumors, oligodendrogliomas

\section{Introduction}

Glial tumors represent a heterogeneous group of neoplasms [1]. These tumors are of great interest to target therapy, because they are neoplasias that are frequently resistant to the types of treatment available [2]. In this group we may remember the example of oligodendrogliomas that are rare neoplasms affecting the central nervous system (CNS) with a slow and infiltrative growth, accounting for $4-5 \%$ of primary central ner-

\footnotetext{
* Corresponding author: Laboratório de Pesquisa em Patologia Universidade Federal de Ciências da Saúde de Porto Alegre (UFCSPA), Porto Alegre, Brazil. Tel.: +55 5133038802; E-mail: lisi.zavalhia@hotmail.com.
}

vous system $[3,4]$. These tumors arise from the oligodendrocytes that comprise the main glial cell types in the CNS, being responsible for producing the myelin that forms sheaths around axons [5].

Ependymomas are also glial neoplasias that constitute $6 \%$ to $10 \%$ of brain tumors in children. These are the third most common histological type in this age group, and are up to $4 \%$ of brain tumors in adults [6-8]. These tumors arise from the ependymal cells lining the ventricles of the brain and the central canal of the spinal cord [9].

C-kit is a proto-oncogene located on the long arm of chromosome 4 that encodes kit (CD117), a membrane-bound glycoprotein of type III receptor tyrosine kinase. Its ligand is the stem cell factor (SCF) [10-19]. 
The receptor tyrosine kinase, Kit, normally controls the function of melanocytes, primitive hematopoietic cells and germ cells [20] $C$-kit appears to play a central role in cellular proliferation and differentiation, and has been shown to be involved in the pathogenesis of several neoplasms such as lung, breast, skin, uterus, bladder and ovarian cancers, leukemias, germ cell tumors, Ewing sarcoma and gastrointestinal stromal tumors (GISTs) [1,19,21-30]. Oncogenic c-kit mutation is found most commonly in exon 11, but gainof-function mutation of exons 9,13 , and 17 have also been reported [13,18,31-33]. Due to their important role in cell proliferation, apoptosis, neurotransmission and oncogenesis, protein kinases have become major targets for research [34].

Different types of gain-of-function of $c$-kit including point mutations, deletions and duplications, have been documented [35]. The c-Kit activation through mutations leads to different neoplasms types, as GISTs, germ cell tumors, small cell lung carcinomas and some leukemias [17]. Gain-of-function of receptor tyrosine kinases is a widely occurring event in the progress towards cancer [20]. Mutations in c-kit were shown to result in increased tyrosine kinase activity in the absence of the ligand, as has been observed in gastrointestinal stromal tumors (GIST) [36,37]. These alterations can result in a strong oncogenic potential $[18,33,35,38]$. In this context, the use of a tyrosine kinase inhibitor, imatinib mesylate, leads to the onset of apoptosis and decreased proliferation, resulting in a significant increase in survival $[39,40]$.

Literature about GISTs suggests that tumors that often carry activating mutations in the $c$-kit, probably have effective response to receptor kinase inhibitors, so, its expression may be used as a tumor marker and as a prognostic factor [41].

Cellular resistance to antineoplastic drugs can be considered one of the biggest barriers with regard to effective treatment of malignant tumors in general [4245]. Due to this fact, protein kinases have become a new possibility in research and are becoming a target for potent new drugs that have the specific intent to inhibit these proteins [46].

Considering the effectiveness of therapy with selective inhibitors of receptor kinases in GISTs based on the findings of positivity for CD117, the present study aimed to investigate the expression of CD117 in certain glial tumors. This expression may be used as a tumor marker as well as a therapeutical target.

\section{Material and methods}

\subsection{Sample}

$55(n=55)$ tumors obtained from the archives of the Department of Pathology of the Universidade Federal de Ciências da Saude de Porto Alegre (UFCSPA), from patients in three neurosurgery centers in the city of Porto Alegre, Southern Brazil, in the period 19681997, whose anatomicopathological and IHC examination led to the diagnosis of ependymoma $(n=34)$ and oligodendroglioma $(n=21)$, according to World Health Organization criteria [47].

\subsection{Procedures}

Clinical data were collected from medical records which included: sex, age at diagnosis and tumor grade.

All cases were reviewed according to the current World Health Organization criteria and by an experienced neuropathologist. Immunohistochemical analysis was performed on $4 \mu \mathrm{m}$-thick, formalinfixed, paraffin-embedded tissue sections using primary antibody polyclonal rabbit anti-human c-kit-CD117 (DAKO, Carpinteria, CA, USA, dilution 1:50). Tissue sections were deparaffinized, then incubated for antigen retrieval in a citrate buffer $(\mathrm{pH}$ 6.0) for $30 \mathrm{~min}$ in a water bath at $95-99^{\circ} \mathrm{C}$. After cooling (30 min), endogenous peroxidase activity was blocked by immersing the slides into $\mathrm{H}_{2} \mathrm{O}_{2} 5 \%(3 \times 10 \mathrm{~min})$. Subsequently, the slides were rinsed twice with phosphate buffer saline (PBS) and then incubated in a protein solution to block unspecific bindings (bovine serum albumin 1\%). The rabbit polyclonal anti-human antibody c-kit (CD117, Dako) at 1:50 dilution was applied and incubated for 60 minutes. After another PBS rinsing, the histological sections were incubated with the secondary antibody (DAKO advance ${ }^{\mathrm{TM}}$ HRP link) for 30 minutes, then again rinsed with PBS and incubated with tertiary antibody (DAKO Advance ${ }^{\text {TM }}$ HRP enzyme) for 30 minutes. The antigen-antibody was visualized with diamino-benzidine tetrachloride (DAB) and counterstained with hematoxylin.

GIST samples were used as control for each step. Negative control was performed by eliminating the primary antibody, which was replaced by bovine serum albumin (1\%).

\subsection{Immunohistochemical analysis}

The stained samples were numbered and assessed by two researchers to determine: the presence $(+)$ or ab- 
Table 1

Clinical characterization of patients

\begin{tabular}{lcc}
\hline & $\begin{array}{c}\text { Ependymomas } \\
(n=34)\end{array}$ & $\begin{array}{c}\text { Oligodendrogliomas } \\
(n=21)\end{array}$ \\
\hline Sex (male) & $21(61.8 \%)$ & $15(71.4 \%)$ \\
Age at diagnosis (years) & $6.50(1-65)^{\mathrm{a}}$ & $38.7 \pm 16.52^{\mathrm{b}}$ \\
Tumor grade & & \\
$\quad$ Low grade (II) & $21(61.8 \%)$ & $11(52.4 \%)$ \\
$\quad$ High grade (III) & $13(38.2 \%)$ & $10(47.6 \%)$ \\
\hline
\end{tabular}

${ }^{a}$ Value expressed as median, minimum and maximum.

${ }^{b}$ Value expressed as mean \pm standard deviation.

sence (-) of immunostaining for CD117, location (cytoplasm, membrane), the distribution of positive cells $(\leqslant 10 \%=$ focal, moderate $=11-50 \%>50 \%=$ diffuse) (Table 2). Here, we considered as absent CD117 protein expression when was not observed any reaction in the IHQ.

\subsection{Statistical analysis}

Statistical analysis was performed using SPSS software (version 16.0). In ependymomas the age at diagnosis was expressed as median, minimum and maximum, whereas in oligodendrogliomas it was expressed as mean \pm standard deviation, according to the distribution of the variables. The association between CD117 expression and tumor grade was examined using the Fisher's exact test. CD117 expression and ependymoma age at diagnosis was evaluated with Kruskal-Wallis test, whereas for oligodendroglioma was used ANOVA test. Significance was defined as $p<0.05$.

\subsection{Ethics}

The study was approved by the Ethical Research Committee of Universidade Federal de Ciências da Saúde de Porto Alegre, Porto Alegre, Brazil (1132/10).

\section{Results}

The study group was composed of 55 glial tumors ( 34 ependymomas and 21 oligodendrogliomas). The sample was composed mainly of males ( $n=36,65.53 \%)$. The median age at diagnosis was 6.5 (1-65) years in ependymomas, and the average age of 38.7 years \pm 16.52 in oligodendrogliomas. Twenty-one $(61.8 \%)$ ependymomas were classified as low-grade malignancy (grade II) and $13(38.2 \%)$ classified as grade III malignancy. Eleven (52.4\%) oligodendrogliomas were classified as low-grade malignancy (grade II) and 10 $(47.6 \%)$ classified as anaplastic oligodendrogliomas (grade III). Grade II tumors were more frequent than grade III tumors in both histological types studied. We observed that lesions considered more aggressive were less frequent in our sample (Table 1). Immunoreactivity for CD117 protein was observed in $25.5 \%$ of tumors distributed in both histological types, exhibiting immunoreactivity in neoplastic cells and also in tumor parenchyma (Table 2). The expression of CD117 in GIST (positive control) was predominantly cytoplasmic with membranous accentuation (Fig. 1).

\subsection{CD117 expression in ependymomas}

CD117 positivity was detected in 7 (20.6\%) of the 34 ependymomas. Staining reveals focal cytoplasmic localization of CD117 and expression moderate in ependymal rosettes, typical feature of these tumors (Fig. 2). There was no association between age at diagnosis $(p>0.05)$ and/or tumor grade $(p>0.05)$ and positivity for CD117.

\subsection{CD117 expression in oligodendrogliomas}

CD117 positivity was detected in $7(33.3 \%)$ of the 21 oligodendrogliomas. Six (60\%) anaplastic oligodendrogliomas showed cytoplasmic immunoreactivity for CD117 (Fig. 3). An association was observed between age at diagnosis and positivity of CD117 $(p=0.039)$. Higher tumor grade (grade III) was also associated with positivity of CD117 ( $p=0.007)$. The comparison between tumor grade and CD117 positivity distribution showed that, of eleven patients with low-grade oligodendrogliomas (Grade II), only one had focal positivity. On the other hand, in ten patients with anaplastic oligodendrogliomas (Grade III), six had moderate and diffuse expression (Table 2).

\section{Discussion}

To date, few studies have assessed the activity of CD117 in ependymomas and oligodendrogliomas; therefore, its activity remains uncertain. The present study indicates that CD117 is moderately expressed in tumors derived from glial cells. However, we observed that in ependymomas the expression of CD117 does not seem to be directly associated with disease parameters (grade, age at diagnosis). Interestingly, we showed in our study that the evaluation of CD117 in oligodendrogliomas has an association with older age at diagnosis and disease aggressiveness. 
Table 2

Immunohistochemical expression of CD117

\begin{tabular}{|c|c|c|c|c|c|}
\hline \multirow{3}{*}{ Glial tumors/ Grade } & \multicolumn{4}{|c|}{ CD117 expression in tumors } & \multirow{3}{*}{ C-kit+ / Total } \\
\hline & \multirow[t]{2}{*}{ Absent } & Present $\leqslant 10 \%$ & Present $11-50 \%$ & Present $>50 \%$ & \\
\hline & & Focal & Moderate & Diffuse & \\
\hline Ependymoma II & $16(76.2 \%)$ & 3 & 2 & 0 & $5 / 21(23.8 \%)$ \\
\hline Ependymoma III & $11(84.6 \%)$ & 1 & 1 & 0 & $2 / 13(15.4 \%)$ \\
\hline Oligodendroglioma II & $10(90.9 \%)$ & 1 & 0 & 0 & $1 / 11(9.1 \%)$ \\
\hline Oligodendroglioma III & $4(40 \%)$ & & 3 & 3 & $6 / 10(60 \%)$ \\
\hline Total & $41(74.5 \%)$ & $5(9.1 \%)$ & $6(10.9 \%)$ & $3(5.5 \%)$ & $14(25.5 \%)$ \\
\hline
\end{tabular}

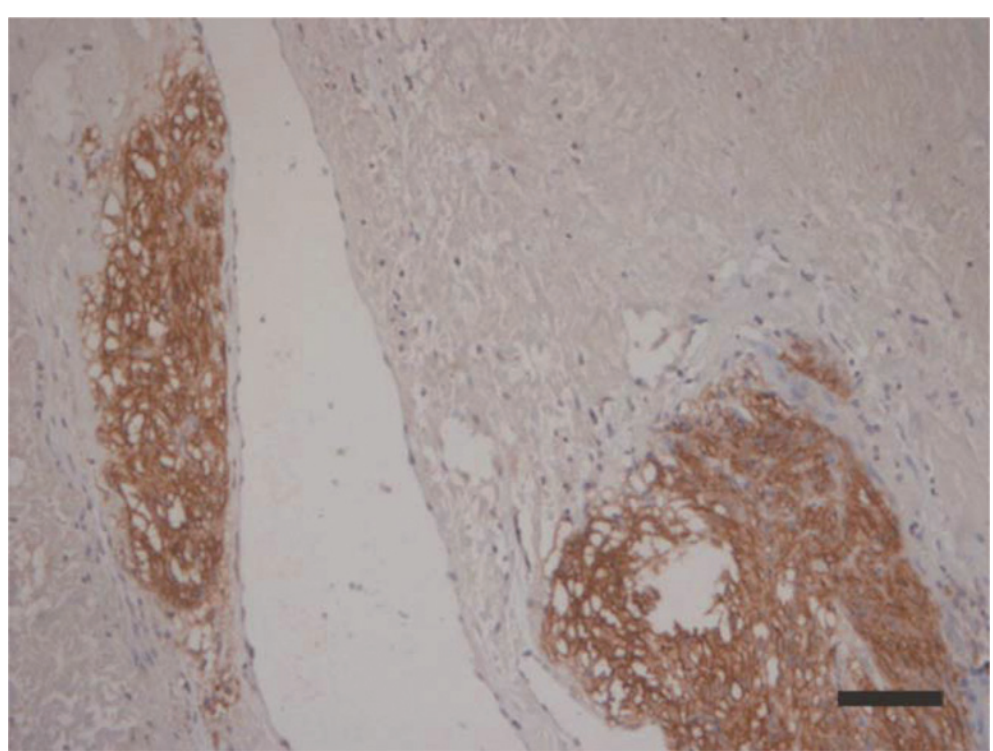

Fig. 1. CD117 staining in gastrointestinal stromal tumors (GISTs) (original magnification $=200 x$ ). Scale bar, $50 \mu \mathrm{m}$.

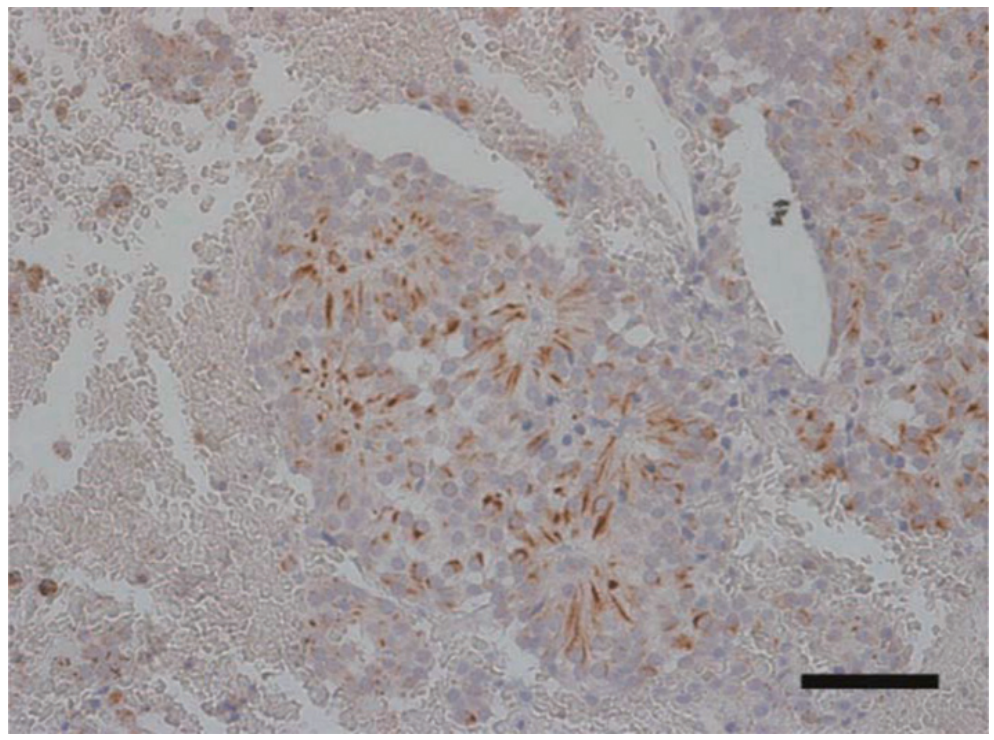

Fig. 2. Staining reveals focal cytoplasmic localization of CD117 and expression moderate in ependymal rosettes (original magnification $=400 \mathrm{x})$. Scale bar, $50 \mu \mathrm{m}$. 

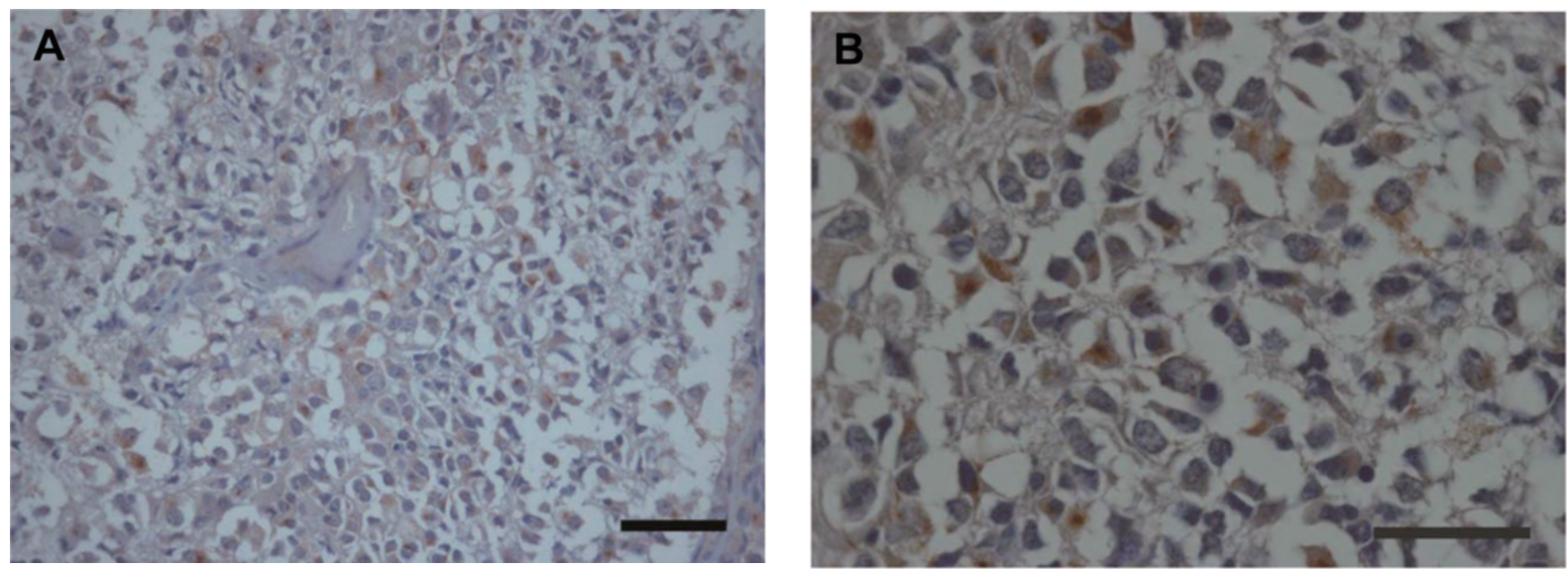

Fig. 3. A. Immunohistochemical staining showing a cytoplasmic CD117 expression in anaplastic oligodendroglioma (original magnification $=$ 400x). B. Expression of CD117 in the cytoplasm of isolated cells (original magnification $=1000 \mathrm{x}$ ) Scale bars, $50 \mu \mathrm{m}$.

Ependymomas affect patients in all age groups; however, they are present with a bimodal distribution with a peak in the first two decades and another peak between thirty and forty years [9]. Differently, oligodendrogliomas affect mostly adults, with a peak incidence in the fifth and sixth decades of life [48]. This distribution was also observed in our group of patients so it seems to be representative.

There are really very few studies about CD117 expression and brain tumors. In 2005, Cetin et al. showed a higher expression of CD117 in anaplastic oligodendrogliomas [49]. Later on in a model experimental study involving pediatric tumors, the authors observed that the CD117 was moderately expressed in the endothelium of ependymomas [50]. In our study, the expression of CD117 was moderately detected in oligodendrogliomas and ependymomas (25.5\% of global expression) and was most evident in high grade oligodendrogliomas (grade III). That data is also in accordance with what was previously described in the literature [49, $51,52]$.

The immunoreactivity of CD117 in both histological types was citoplasmatic predominantly. How kit is membrane bound receptor, the CD117 expression in both, cytoplasm and membrane, should be considered. Moreover, in the literature there are not studies concerning important differences between cytoplasmic and membrane staining in GISTs [53].

Dehghan et al., 2010, observed CD117 immunoreactivity in $42 \%$ of gliomas evaluated. High-grade tumors had a higher proportion of CD117 expression than lowgrade ones, and the highest staining grades were found in glioblastomas, anaplastic oligodendrogliomas, and anaplastic ependymomas [54]. In contrast recent stud- ies demonstrated that the frequency of CD117 expression was not different between the low-grade and high-grade gliomas $[55,56]$. However, Mahzouni and Jafari, 2012, found that the highest percentages of CD117 stained cells were observed among high-grade tumors [56]. These results are in agreement with our findings that shown that more aggressive tumors have higher expression of CD117. Perhaps these tumors with higher malignancy may be candidates for treatment with selective inhibitors of tyrosine kinases.

$C$-kit has been suggested to be very important in growth and progression of various tumors, and recent studies support the view that $c$-kit is involved in glioma tumorigenesis $[52,57,58]$. KIT is a mediator in the activation of many downstream protein effectors, the Interaction of SCF/KIT induces several downstream signaling pathways, including PI3K/AKT and JAK/STAT cascades, which play a role in a number of cellular functions including proliferation, differentiation, cell cycle regulation and apoptosis [59]. A better understanding of signaling pathways regulated by KIT, can contribute significantly to new therapeutic strategies.

Several approaches and numerous clinical trials are currently testing the efficacy of novel therapies against malignant gliomas $[60,61]$. Inhibition of tyrosine kinase receptors by synthetic small molecules has become a promising new therapy option in oncology [62].

Novel approaches using the oral agent STI-571 (Gleevec ${ }^{\circledR}$ ), a tyrosine kinase inhibitor, have shown significant responses in patients with gastrointestinal stromal tumor and chronic myelogenous leukemia based on the expression of CD117 [22]. The receptor tyrosine kinase Kit is a potential target for signal transduction therapy in many neoplasms [63]. 
Our findings demonstrate that a proportion of ependymomas and oligodendrogliomas are positive for CD117 expression. Thus, we suppose that evaluation the expression of this receptor could be important, and these tumors may be potential candidates for treatment with tyrosine kinase inhibitors. However, additional analysis as by polymerase chain reaction (PCR) and/or western-blotting techniques, are necessary to confirm these findings and also clinical studies are required to evaluate the possibility of new therapeutic approaches in specific cases.

\section{Acknowledgments}

We wish to thank the Post-graduate Program in Pathology of the Universidade Federal de Ciências da Saúde de Porto Alegre and the Brazilian Ministry of Education and Culture for the financial support (CAPES and $\mathrm{CNPq}$ ).

\section{References}

[1] P.G. Morris and L.E. Abrey, Novel targeted agents for plateletderived growth factor receptor and c-kit in malignant gliomas, Target Oncol 5 (2010), 193-200.

[2] P. Kinsella, M. Clynes and V. Amberger-Murphy, Imatinib and docetaxel in combination can effectively inhibit glioma invasion in an in vitro $3 \mathrm{~d}$ invasion assay, J Neurooncol 101 (2011), 189-198

[3] S.J. Mork, K.F. Lindegaard, T.B. Halvorsen, E.H. Lehmann, T. Solgaard, R. Hatlevoll, S. Harvei and J. Ganz, Oligodendroglioma: Incidence and biological behavior in a defined population, J Neurosurg 63 (1985), 881-889.

[4] J.S. Reis Filho, M.R. Netto, B.G. Sluminsky, L.A. Delle, A. Antoniuk, R. Ramina and L.F. Torres, Oligodendroglioma: A pathological and clinical study of 15 cases, Arq Neuropsiquiatr 57 (1999), 249-254.

[5] J.S. Lee, A. Padmanabhan, J. Shin, S. Zhu, F. Guo, J.P. Kanki, J.A. Epstein and A.T. Look, Oligodendrocyte progenitor cell numbers and migration are regulated by the zebrafish orthologs of the nf1 tumor suppressor gene, Hum Mol Genet 19 (2010), 4643-4653.

[6] B. Horn, R. Heideman, R. Geyer, I. Pollack, R. Packer, J. Goldwein, T. Tomita, P. Schomberg, J. Ater, L. LuchtmanJones, K. Rivlin, K. Lamborn, M. Prados, A. Bollen, M. Berger, G. Dahl, E. McNeil, K. Patterson, D. Shaw, M. Kubalik and C. Russo, A multi-institutional retrospective study of intracranial ependymoma in children: Identification of risk factors, $J$ Pediatr Hematol Oncol 21 (1999), 203-211.

[7] R. Ruda, M. Gilbert and R. Soffietti, Ependymomas of the adult: Molecular biology and treatment, Curr Opin Neurol 21 (2008), 754-761.

[8] S. Zacharoulis and L. Moreno, Ependymoma: An update, $J$ Child Neurol 24 (2009), 1431-1438.
[9] L.F. Torres, J.S. Reis Filho, M.R. Netto, L.A. Delle, B.G. Sluminsky, F.A. Tironi, A. Antoniuk and R. Ramina, Ependymomas: Clinical, epidemiological and clinico-pathological findings of 22 cases, Arq de Neuropsiquiatr 57 (1999), 261-266.

[10] S. Majumder, K. Brown, F.H. Qiu and P. Besmer, C-kit protein, a transmembrane kinase: Identification in tissues and characterization, Mol Cell Biol 8 (1988), 4896-4903.

[11] D.E. Williams, J. Eisenman, A. Baird, C. Rauch, K. Van Ness, C.J. March, L.S. Park, U. Martin, D.Y. Mochizuki, H.S. Boswell et al., Identification of a ligand for the c-kit protooncogene, Cell 63 (1990), 167-174.

[12] H. Vliagoftis, A.S. Worobec and D.D. Metcalfe, The protooncogene c-kit and c-kit ligand in human disease, J Allergy Clin Immunol 100 (1997), 435-440.

[13] M.L. Lux, B.P. Rubin, T.L. Biase, C.J. Chen, T. Maclure, G. Demetri, S. Xiao, S. Singer, C.D. Fletcher and J.A. Fletcher, Kit extracellular and kinase domain mutations in gastrointestinal stromal tumors, Am J Pathol 156 (2000), 791-795.

[14] L.W. Elmore, K. Domson, J.R. Moore, M. Kornstein and R.T. Burks, Expression of c-kit (cd117) in benign and malignant human endometrial epithelium, Arch Pathol Lab Med 125 (2001), 146-151.

[15] C.D. Mol, K.B. Lim, V. Sridhar, H. Zou, E.Y. Chien, B.C. Sang, J. Nowakowski, D.B. Kassel, C.N. Cronin and D.E. McRee, Structure of a c-kit product complex reveals the basis for kinase transactivation, J Biol Chem 278 (2003), 3146131464 .

[16] J. Lennartsson, T. Jelacic, D. Linnekin and R. Shivakrupa, Normal and oncogenic forms of the receptor tyrosine kinase kit, Stem Cells 23 (2005), 16-43.

[17] M. Miettinen and J. Lasota, Kit (cd117): A review on expression in normal and neoplastic tissues, and mutations and their clinicopathologic correlation, Appl Immunohistochem Mol Morphol 13 (2005), 205-220.

[18] I. Do, E.S. Araujo, R.K. Kalil, P. Bacchini, F. Bertoni, K.K. Unni and Y.K. Park, Protein expression of kit and gene mutation of c-kit and pdgfrs in ewing sarcomas, Pathol Res Pract 203 (2007), 127-134

[19] I. Sulzbacher, P. Birner, C. Toma, N. Wick and P.R. Mazal, Expression of c-kit in human osteosarcoma and its relevance as a prognostic marker, J Clin Pathol 60 (2007), 804-807.

[20] J. Lennartsson and L. Ronnstrand, The stem cell factor receptor/ c-kit as a drug target in cancer, Curr Cancer Drug Targets 6 (2006), 65-75.

[21] F.H. Qiu, P. Ray, K. Brown, P.E. Barker, S. Jhanwar, F.H. Ruddle and P. Besmer, Primary structure of c-kit: Relationship with the csf-1/pdgf receptor kinase family-oncogenic activation of v-kit involves deletion of extracellular domain and $\mathrm{c}$ terminus, EMBO J 7 (1988), 1003-1011.

[22] B.E. Smithey, A.S. Pappo and D.A. Hill, C-kit expression in pediatric solid tumors: A comparative immunohistochemical study, Am J Surg Pathol 26 (2002), 486-492.

[23] K.J. Butnor, J.L. Burchette, T.A. Sporn, S.P. Hammar and V.L. Roggli, The spectrum of kit (cd117) immunoreactivity in lung and pleural tumors: A study of 96 cases using a single-source antibody with a review of the literature, Arch Pathol Lab Med 128 (2004), 538-543.

[24] P.T. Went, S. Dirnhofer, M. Bundi, M. Mirlacher, P. Schraml, S. Mangialaio, S. Dimitrijevic, J. Kononen, A. Lugli, R. Simon and G. Sauter, Prevalence of kit expression in human tumors, J Clin Oncol 22 (2004), 4514-4522.

[25] K. Nakagawa, Y. Matsuno, H. Kunitoh, A. Maeshima, H. Asamura and R. Tsuchiya, Immunohistochemical kit (cd117) 
expression in thymic epithelial tumors, Chest 128 (2005), 140144.

[26] E. Jost, L. Michaux, M. Vanden Abeele, B. Boland, D. Latinne, C. Godfraind, J.M. Scheiff, J.L. Vaerman, F. Lecouvet and A. Ferrant, Complex karyotype and absence of mutation in the ckit receptor in aggressive mastocytosis presenting with pelvic osteolysis, eosinophilia and brain damage, Ann Hematol 80 (2001), 302-307.

[27] S. Bonilla, P. Alarcon, R. Villaverde, P. Aparicio, A. Silva and S. Martinez, Haematopoietic progenitor cells from adult bone marrow differentiate into cells that express oligodendroglial antigens in the neonatal mouse brain, Eur J Neurosci 15 (2002), 575-582.

[28] J.L. Hornick and C.D. Fletcher, Immunohistochemical staining for kit (cd117) in soft tissue sarcomas is very limited in distribution, Am J Clin Pathol 117 (2002), 188-193.

[29] C.X. Pan, X.J. Yang, A. Lopez-Beltran, G.T. MacLennan, J.N Eble, M.O. Koch, T.D. Jones, H. Lin, K. Nigro, V. Papavero, M. Tretiakova and L. Cheng, C-kit expression in small cell carcinoma of the urinary bladder: Prognostic and therapeutic implications, Mod Pathol 18 (2005), 320-323.

[30] A. Kondi-Pafiti, N. Arkadopoulos, C. Gennatas, V. Michalaki, M. Frangou-Plegmenou and P. Chatzipantelis, Expression of c-kit in common benign and malignant breast lesions, Tumori 96 (2010), 978-984.

[31] B.P. Rubin, S. Singer, C. Tsao, A. Duensing, M.L. Lux, R. Ruiz, M.K. Hibbard, C.J. Chen, S. Xiao, D.A. Tuveson, G.D. Demetri, C.D. Fletcher and J.A. Fletcher, Kit activation is a ubiquitous feature of gastrointestinal stromal tumors, Cancer Res 61 (2001), 8118-8121.

[32] M.C. Heinrich, B.P. Rubin, B.J. Longley and J.A. Fletcher, Biology and genetic aspects of gastrointestinal stromal tumors: Kit activation and cytogenetic alterations, Hum Pathol 33 (2002), 484-495.

[33] T.W. Kim, H. Lee, Y.K. Kang, M.S. Choe, M.H. Ryu, H.M. Chang, J.S. Kim, J.H. Yook, B.S. Kim and J.S. Lee, Prognostic significance of c-kit mutation in localized gastrointestinal stromal tumors, Clin Cancer Res 10 (2004), 3076-3081.

[34] M.H. Cobb, Map kinase pathways, Prog Biophys Mol Biol 71 (1999), 479-500.

[35] C.E. Edling and B. Hallberg, C-kit-a hematopoietic cell essential receptor tyrosine kinase, Int J Biochem Cell Biol 39 (2007), 1995-1998.

[36] C.L. Corless, L. McGreevey, A. Haley, A. Town and M.C. Heinrich, Kit mutations are common in incidental gastrointestinal stromal tumors one centimeter or less in size, Am J Pathol 160 (2002), 1567-1572.

[37] S. Hirota, A. Ohashi, T. Nishida, K. Isozaki, K. Kinoshita, Y. Shinomura and Y. Kitamura, Gain-of-function mutations of platelet-derived growth factor receptor alpha gene in gastrointestinal stromal tumors, Gastroenterology 125 (2003), 660667.

[38] C. Willmore, J.A. Holden, L. Zhou, S. Tripp, C.T. Wittwer and L.J. Layfield, Detection of c-kit-activating mutations in gastrointestinal stromal tumors by high-resolution amplicon melting analysis, Am J Clin Pathol 122 (2004), 206-216.

[39] J.M. Goldman and J.V. Melo, Targeting the bcr-abl tyrosine kinase in chronic myeloid leukemia, N Engl J Med 344 (2001), 1084-1086.

[40] P. Bumming, J. Andersson, J.M. Meis-Kindblom, H. Klingenstierna, K. Engstrom, U. Stierner, B. Wangberg, S. Jansson, H. Ahlman, L.G. Kindblom and B. Nilsson, Neoadjuvant, adjuvant and palliative treatment of gastrointestinal stro- mal tumours (gist) with imatinib: A centre-based study of 17 patients, Br J Cancer 89 (2003), 460-464.

41] E. Wardelmann, S. Merkelbach-Bruse, R. Buttner and H.U. Schildhaus, [activating mutations in receptor tyrosine kinases with relevance for treatment of gastrointestinal stromal tumors], Verh Dtsch Ges Pathol 91 (2007), 165-168.

[42] C.P. Leith, K.J. Kopecky, I.M. Chen, L. Eijdems, M.L. Slovak, T.S. McConnell, D.R. Head, J. Weick, M.R. Grever, F.R. Appelbaum and C.L. Willman, Frequency and clinical significance of the expression of the multidrug resistance proteins mdr1/p-glycoprotein, mrp1, and lrp in acute myeloid leukemia: A southwest oncology group study, Blood 94 (1999), 1086-1099.

[43] V.M. Rumjanek, G.S. Trindade, K. Wagner-Souza, M.C. deOliveira, L.F. Marques-Santos, R.C. Maia and M.A. Capella, Multidrug resistance in tumour cells: Characterization of the multidrug resistant cell line k562-lucena 1, An Acad Bras Cienc 73 (2001), 57-69.

[44] S. Fujimaki, T. Funato, H. Harigae, J. Fujiwara, J. Kameoka, K. Meguro, M. Kaku and T. Sasaki, Quantitative analysis of a mdr1 transcript for prediction of drug resistance in acute leukemia, Clin Chem 48 (2002), 811-817.

[45] T. Sakaeda, T. Nakamura and K. Okumura, Mdr1 genotyperelated pharmacokinetics and pharmacodynamics, Biol Pharm Bull 25 (2002), 1391-1400.

[46] A. Arora and E.M. Scholar, Role of tyrosine kinase inhibitors in cancer therapy, J Pharmacol Exp Ther 315 (2005), 971-979.

47] D.N. Louis, H. Ohgaki, O.D. Wiestler, W.K. Cavenee, P.C. Burger, A. Jouvet, B.W. Scheithauer and P. Kleihues, The 2007 who classification of tumours of the central nervous system, Acta Neuropathol 114 (2007), 97-109.

[48] H. El-Hateer, L. Souhami, D. Roberge, R.D. Maestro, R. Leblanc, E. Eldebawy, T. Muanza, D. Melancon, P. Kavan and M.C. Guiot, Low-grade oligodendroglioma: An indolent but incurable disease? Clinical article, J Neurosurg 111 (2009), 265-271.

[49] N. Cetin, G. Dienel and M. Gokden, Cd117 expression in glial tumors, J Neurooncol 75 (2005), 195-202.

[50] M. Puputti, O. Tynninen, P. Pernila, M. Salmi, S. Jalkanen, A. Paetau, H. Sihto and H. Joensuu, Expression of kit receptor tyrosine kinase in endothelial cells of juvenile brain tumors, Brain Pathol 20 (2010), 763-770.

[51] D.A. Kristt, E. Reedy and Y. Yarden, Receptor tyrosine kinase expression in astrocytic lesions: Similar features in gliosis and glioma, Neurosurgery 33 (1993), 106-115.

[52] H.D. Mennel, M. Hallier-Neelsen, S. Hagner and L. Benes, Two novel cell specific receptor proteins, crlr and cd 117 in human glial tumors, Clin Neuropathol 25 (2006), 107-114.

[53] P.R. Pereira, A.N. Odashiro, J.C. Marshall, Z.M. Correa, R. Belfort, Jr. and M.N. Burnier, Jr., The role of c-kit and imatinib mesylate in uveal melanoma, J Carcinog 4 (2005), 19.

[54] A. Dehghan, H. Mahjoub and A. Rajeipour, Determination of cd117 expression in glial tumors and its comparison between high grade and low grade tumors, GJMR 10 (2010), 26-30.

[55] A.L. Gomes, J.S. Reis-Filho, J.M. Lopes, O. Martinho, M.B. Lambros, A. Martins, F. Schmitt, F. Pardal and R.M. Reis, Molecular alterations of kit oncogene in gliomas, Cell Oncol 29 (2007), 399-408.

[56] P. Mahzouni and M. Jafari, The study of cd117 expression in glial tumors and its relationship with the tumor-type and grade, J Res Med Sci 17 (2012), 159-163.

[57] M. Stanulla, K. Welte, M.R. Hadam and T. Pietsch, Coexpression of stem cell factor and its receptor c-kit in human malignant glioma cell lines, Acta Neuropathol 89 (1995), 158-165. 
[58] T. Blom, H. Fox, A. Angers-Loustau, K. Peltonen, L. Kerosuo, K. Wartiovaara, M. Linja, O.A. Janne, P. Kovanen, H. Haapasalo and N.N. Nupponen, Kit overexpression induces proliferation in astrocytes in an imatinib-responsive manner and associates with proliferation index in gliomas, Int $J$ Cancer 123 (2008), 793-800.

[59] W. Hamel and M. Westphal, The road less travelled: C-kit and stem cell factor, J Neurooncol 35 (1997), 327-333.

[60] G. Dresemann, Imatinib and hydroxyurea in pretreated progressive glioblastoma multiforme: A patient series, Ann Oncol 16 (2005), 1702-1708.

[61] D.A. Reardon, M.J. Egorin, J.A. Quinn, J.N. Rich, S. Gururangan, J.J. Vredenburgh, A. Desjardins, S. Sathornsumetee, J.M. Provenzale, J.E. Herndon, 2nd, J.M. Dowell, M.A.
Badruddoja, R.E. McLendon, T.F. Lagattuta, K.P. Kicielinski, G. Dresemann, J.H. Sampson, A.H. Friedman, A.J. Salvado and H.S. Friedman, Phase ii study of imatinib mesylate plus hydroxyurea in adults with recurrent glioblastoma multiforme, J Clin Oncol 23 (2005), 9359-9368.

[62] C. Haberler, E. Gelpi, C. Marosi, K. Rossler, P. Birner, H. Budka and J.A. Hainfellner, Immunohistochemical analysis of platelet-derived growth factor receptor-alpha, -beta, c-kit, cabl, and arg proteins in glioblastoma: Possible implications for patient selection for imatinib mesylate therapy, J Neurooncol 76 (2006), 105-109.

[63] S. Scholl, C. Kirsch, F.D. Bohmer and R. Klinger, Signal transduction of c-kit receptor tyrosine kinase in chrf myeloid leukemia cells, J Cancer Res Clin Oncol 130 (2004), 711-718. 


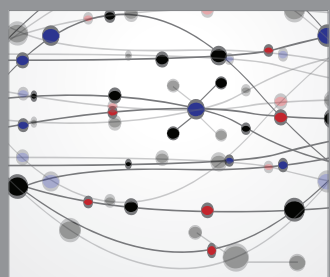

The Scientific World Journal
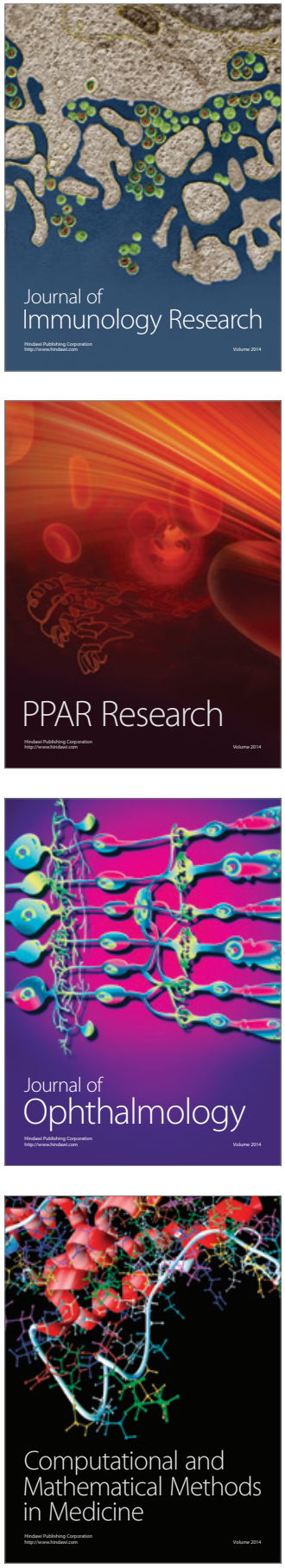

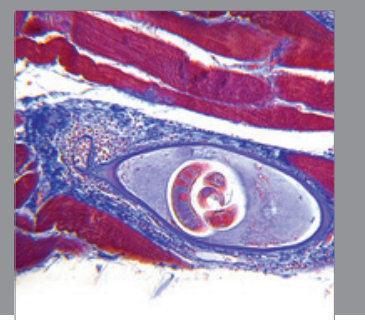

Gastroenterology

Research and Practice
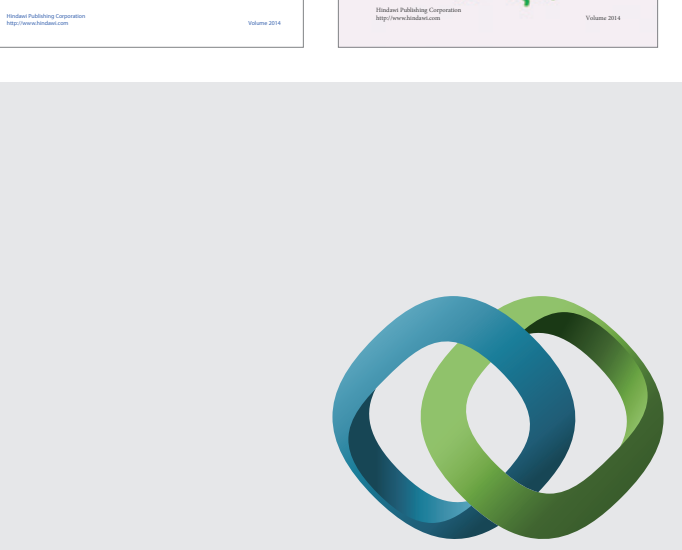

\section{Hindawi}

Submit your manuscripts at

http://www.hindawi.com
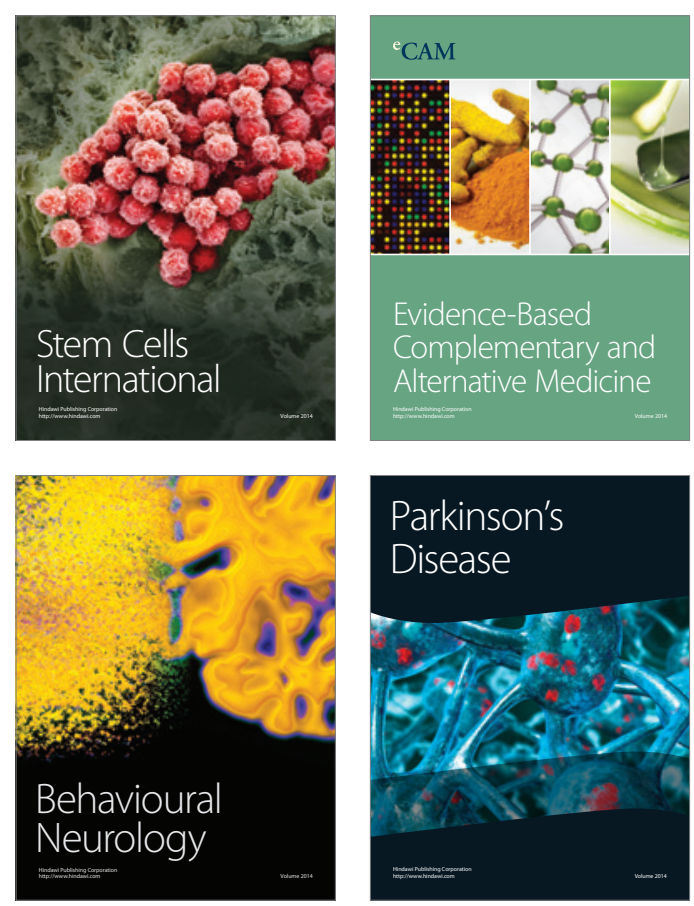

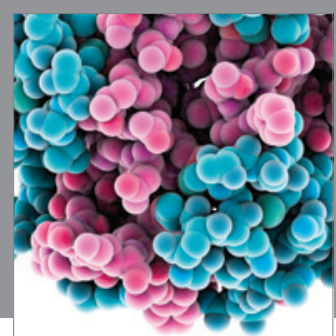

Journal of
Diabetes Research

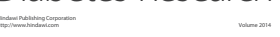

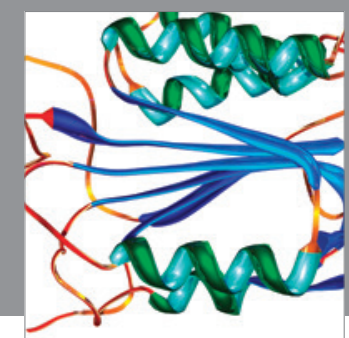

Disease Markers
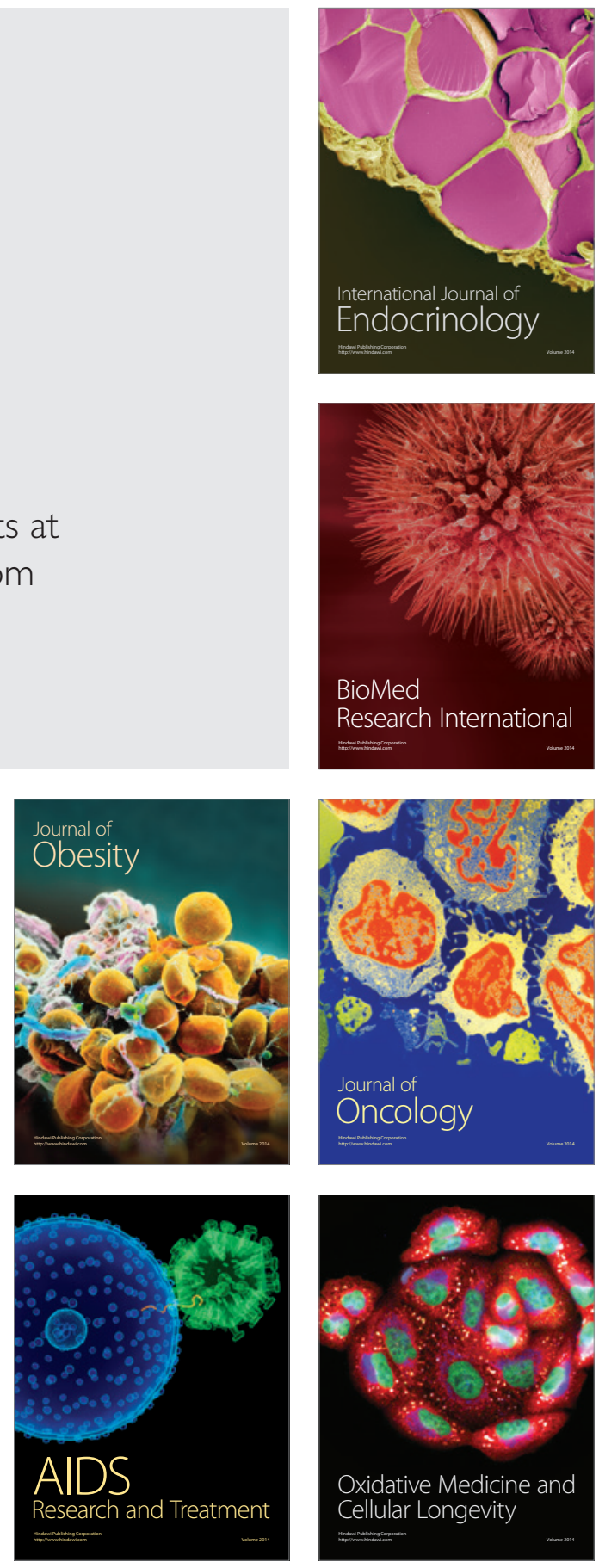